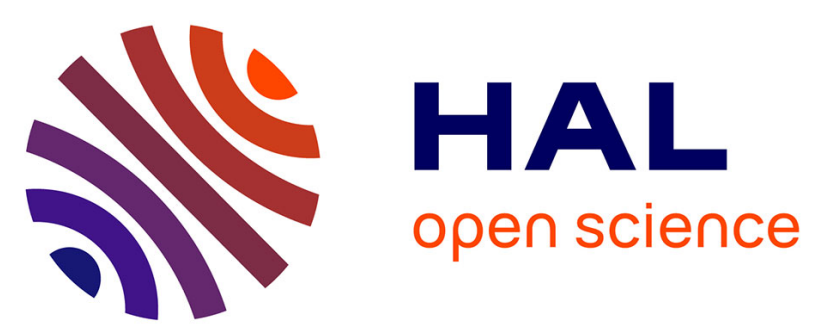

\title{
Influence of damage accumulation under fatigue loading on the AE-based health assessment of composite materials : wave distortion and AE-features evolution as a function of damage level
}

Mohamed Kharrat, Vincent Placet, Emmanuel Ramasso, Lamine Mohamed Boubakar

\section{To cite this version:}

Mohamed Kharrat, Vincent Placet, Emmanuel Ramasso, Lamine Mohamed Boubakar. Influence of damage accumulation under fatigue loading on the AE-based health assessment of composite materials: wave distortion and AE-features evolution as a function of damage level. Composites Part A: Applied Science and Manufacturing, 2018, 10.1016/j.compositesa.2016.03.020, 109, pp.615 - 627. hal-03427018

\author{
HAL Id: hal-03427018 \\ https://hal.science/hal-03427018
}

Submitted on 12 Nov 2021

HAL is a multi-disciplinary open access archive for the deposit and dissemination of scientific research documents, whether they are published or not. The documents may come from teaching and research institutions in France or abroad, or from public or private research centers.
L'archive ouverte pluridisciplinaire HAL, est destinée au dépôt et à la diffusion de documents scientifiques de niveau recherche, publiés ou non, émanant des établissements d'enseignement et de recherche français ou étrangers, des laboratoires publics ou privés. 


\title{
Influence of damage accumulation under fatigue loading on the AE-based health assessment of composite materials: Wave distortion and AE-features evolution as a function of damage level
}

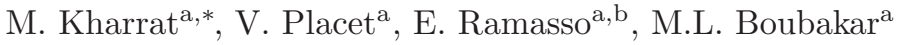 \\ ${ }^{a}$ Department of Applied Mechanics \\ ${ }^{b}$ Department of Automatic Control and Micro-Mechatronic Systems \\ FEMTO-ST Institute - UMR CNRS 6174 - UBFC/ENSMM/UTBM, 25000 Besançon, France
}

\begin{abstract}
Pattern recognition of Acoustic Emission (AE) data is generally performed based on prior knowledge about the acoustic signatures of material damage mechanisms. Traditionally, these signatures are implicitly assumed to be unaffected by damage accumulation during the fatigue life of the material. This study investigates the influence of cumulated damage under cyclic loading on the acoustic signatures of local fracture mechanisms in composites. Artificial AE sources are created using an ultrasonic transmitter and a Pencil Lead Break in order to reproduce various real-like AEs, such that the waveforms, measured at the sensor level, are characterized as similar to real acoustic signatures of local fractures in carbon/epoxy composites. It is shown that these waveforms are distorted with damage accumulation in both time and frequency domains, leading to important changes in the AE-features used in data classification. Consequently, this can engender unreliable statistical representation of the AE sources in such non-stationary media.
\end{abstract}

Keywords: A. Carbon fiber, B. Fatigue, B. Fracture, D. Acoustic emission.

\section{Introduction}

During the last decades, an increasing use of Organic Matrix Composites (OMC) has been noted in several application fields such as aerospace, civil engineering, and automotive industry due to the improvement of their mechanical properties [1-3]. In order to ensure the structural integrity of OMC structures in real time, continuous condition monitoring techniques have been developed, in particular based on Acoustic Emission (AE) [4-7]. When the structure is subjected to solicitations, a stress field is generated leading to microstructural changes. A transient elastic energy is then released, producing ultrasonic waves that propagate through the material. This wave propagation involves a surface vibration that can be measured using appropriate sensors. The form and characteristics of the generated transient signals are directly dependent on the local fracture mechanisms, such as delamination, matrix cracking, fiber/matrix debonding, fiber breakage and fiber pull-out. Each damage mechanism is

\footnotetext{
* Corresponding author. Current address: Laboratory of Optimization and Reliability in Structural Mechanics (LOFIMS), National Institute of Applied Sciences of Rouen, Avenue de l'université, 76801, Saint Etienne du Rouvray Cedex, France

Email address: mohamed.kharrat@insa-rouen.fr (M. Kharrat)
} 
characterized by a specific acoustic signature. The AE technique can be used to discriminate between these damage mechanisms by analyzing the AE signals using appropriate pattern recognition methods, based on prior knowledge of their acoustic signatures.

A pattern recognition method requires the extraction of the relevant $\mathrm{AE}$ features from the $\mathrm{AE}$ hits (such as amplitude, energy, frequency content). Groups of AE features, representing damage mechanisms, are then created using either supervised [8, 9], unsupervised [10-12] or partially-supervised [13] classification methods. The common bedrock of these methods is the use of the AE features while assuming the acoustic signatures unchanged during the fatigue life of the material. However, the acoustic signatures of the damages may evolve due to several factors. Among the factors of influence that have been relatively well studied in the literature, we can mention: sensors technology and associated electronics [14-16], the coupling between the sensor and the material [17, 18], the distance between the acoustic source and the sensor [19-21], the physical properties of the material including material symmetries and wave propagation characteristics (dispersion, attenuation, etc.) [22-25]. The geometry of the specimen is also an important parameter involving the edge effect, the dimensions of the specimens, as well as the interactions with existing discontinuities (holes, rivets, etc.). They potentially lead to wave dispersions and distortions of the AE waveforms [26, 27]. Particularly, the effect of damage accumulation during mechanical loading on the AE features could be substantial. It has been demonstrated that the captured waveforms during tests performed on cementitious materials [28] and bearings [29] have been altered by the damage growth and therefore, the AE features have been influenced. Actually, the discontinuities emerging in the material due to damage disrupt the wave propagation modes and could therefore contribute to a distortion in the detected AE transients emitted from defects. This phenomenon is besides exploited in the nondestructive testing field for damage assessment using Acousto-Ultrasonics (AU).

The AU technique has been developed since several decades as a nondestructive tool for the evaluation of the mechanical properties and the quantification of damage in composite materials. The principle of the technique consists in the excitation of the monitored structure by a particular wave packet emitted from an ultrasonic transducer; a receiver is used to collect the signals transmitted through the damaged area of the material. The recorded waveforms are acquired and processed using an AE-system [30, 31]. The distortion of the waveforms is then studied based on the impact of damage on their AU parameters (AUPs), relatively to the healthy state of the structure. A. Vary has used the $\mathrm{AU}$ for the assessment and quantification of damages in composites materials [32, 33]. Russell-Floyd and Phillips [34] have investigated the detection of deliberately introduced defects in unidirectional carbon-fiber/PEEK laminates by AU and have established the level of confidence with which various defects may be detected in comparisons with healthy laminates. Kwon and Lee [35] have studied the correlation between the amount of artificial defects and the AUPs in adhesively bonded joints of carbon-fiber reinforced plastic (CFRP) laminates and aluminum plates. Peng et al. [36] have used a network of piezoelectric actuators and sensors to characterize the effect of delamination and matrix cracking appearing during cyclic fatigue tests in composites plates on three features of the wave 
signals: amplitude, correlation coefficient and phase change. Maslouhi et al. [37] have used the AU to evaluate unidirectional carbon epoxy composite panels exposed to thermal solicitations. The effect of degradation of the specimens on the AUPs has been quantified leading to classifying them according to the thermal state of degradation. Loutas and Kostopoulos [38, 39] have assessed the damage evolution in woven carbon/carbon composites during cyclic loading tests through extracted AUPs capable of monitoring the progressively developing damage.

All these studies and many others employ $\mathrm{AU}$ as an active control method to monitor the evolution of damages in the material. Moreover, the input signal characteristics are usually not directly related to the AE signatures of damages. As far as the phenomenon of the waveform distortion has been considered and exploited in $\mathrm{AU}$, it has not been taken into account in $\mathrm{AE}$, neither in signal processing nor in data analysis for discriminating damage mechanisms. To the authors' knowledge, the issue of the distortion of the acoustic signatures of fracture mechanisms in composite materials under the effect of damage accumulation and the subsequent impact on the $\mathrm{AE}$ features has not been addressed previously. The quality and relevance of the hits' classification (based on the AE features) could be so greatly impacted, leading to an erroneous structural health assessment. The experimental work presented in this paper focuses on characterizing the influence of damage accumulation in composite materials under cycling fatigue solicitation on the acoustic signatures of the local fracture mechanisms. The evolution of the AE features as a function of the degree of damage is quantified in order to take into account this evolution in the pattern recognition algorithms and properly perform the classification of the $\mathrm{AE}$ events.

Considering the high difficulties that would be encountered to produce and master local fractures in composites, artificial AE sources are preferred, as it is usually performed in AU. The challenge here is twofold:

- Develop artificial AE sources able to generate AE hits having similar characteristics at the sensor level as those obtained from the local fracture mechanisms.

- Ensure the reproducibility of the generated signals in order to allow the comparison between the detected waveforms at different stages during the lifetime of the material.

According to the literature, several methods can be used to generate AEs in composites. The American Society for Testing and Materials (ASTM) has issued a standard guide for determining the reproducibility of the AE sensor response [40] and has recommended three signal sources: a gas-jet, an impulsive source produced by breaking a pencil lead, and an electrically driven ultrasonic transducer. The gas-jet method is performed without a mechanical contact and can be used as a calibration source and to simulate an AE event on the surface of the material [41-43]. Nevertheless, this method can be affected by multiple environmental factors such as temperature and humidity. The pulsed laser is a second contactless method that has been employed to simulate an acoustic emission from crack growth by generating a dipole stress field within the structure [44-46]. It is relatively expensive, requires strict safety considerations and produces low power (to avoid surface damage), thus, weak AE signals. 
The Hsu-Nielsen source [47], namely Pencil Lead Break (PLB), has been widely employed as an artificial AE source using the fracture of a brittle graphite lead in a suitable fitting [48-51]. This break generates an intense acoustic signal - quite similar to a natural AE source - that sensors detect as a strong burst. Usually, this test aims at checking the sensor's coupling and detectability, as well as the accuracy of the source location setup. Practically, the operator presses the lead of a mechanical pencil tightly against the surface of the material. The surface undergoing this pressure is locally deformed. When the lead breaks, the accumulated energy is abruptly released leading to a microscopic displacement of the surface. An acoustic wave is therefore generated and propagates into the structure. The produced waveform is quite similar to that generated by a damage. Hamstad [49] has reported that PLB sources performed on either the top surface or the edge surface of a plate are well represented by interior buried out-of-plane monopole or in-plane monopole sources. Besides, in-plane PLB sources on a plate edge provide displacement signals with relative modal $\left(\mathrm{A}_{0}\right.$ and $\mathrm{S}_{0}$ modes) intensity distributions much closer to those from buried dipoles at the same depths than do surface out-of-plane PLBs. Moreover, another studies have pointed out that PLB is characterized by a fairly good reproducibility, since it depends on several parameters such as the applied force, the angle of orientation and the free length of the lead [52-54].

An AE source can also be simulated using an ultrasonic transducer by generating AE waves on the surface of the material. Due to the vibration of a piezoelectric element, a local deformation of the material's surface is produced and transmitted into the structure in the form of an acoustic wave. The principle of the AU can be used here to reproduce an AE source using a transmitting transducer instead of a real damage. Contrary to conventional AU configuration, the input signal of the ultrasonic transducer used as a transmitter was optimized in our work to obtain damage-like AE signatures at the sensor level. The input-signal was tuned, so that, to obtain damage-like AE waveforms. The AU has the advantage of allowing the control of the input-signal, so that, it can be adapted to obtain a damagelike AE waveform. The generated signals can also be reproduced perfectly. The measured signals can then be processed using the AE system in order to assess the potential distortions. However, some parameters have to be taken into account, such as the type of the transducer used as transmitter, the strength of the emitted signal, the coupling and the contact surface between the transducer and the structure. H.L. Dunegan has reported [55] the possibility to generate signals similar to those produced by a PLB in plates using an ultrasonic transducer as a transmitter having a miniature small aperture.

In this work, an experimental procedure is conducted by creating artificial AE sources in order to reproduce and simulate different damage-like AE sources. An ultrasonic transducer and a PLB are used as artificial AE sources in CFRP specimens undergoing cycling tensile fatigue tests. The artificial AE sources are chosen due to their ease of implementation and manipulation. Their reproducibility is studied and compared by successively emitting a certain number of hits at several instants during the test. An AE sensor is used to collect the signals, from which the hits are extracted and the AE-features are then determined using an appropriate algorithm [56]. 
The evolutions of the waveforms as a function of damage development are quantified in order to guide the pattern recognition tools towards an efficient classification of the AE events according to the damage mechanisms. It should be mentioned that our basic idea, in this work, is not to establish a quantitative relationship between material/experimental parameters and AE-features evolution as a function of damage, nor to use such a relationship to implement supervised clustering approaches. The limitations of such approaches have been clearly pointed out these last years in the literature related to AE monitoring of composite materials. The purpose here is rather to give guidance toward improving the pattern recognition algorithms in order to be able to consider the waveforms evolutions with damage accumulation in the AE-data classification through unsupervised approaches.

\section{Materials and methods}

\subsection{Purpose of the study}

The issue raised in this study and the followed methodology are shown in Figure 1. When defects accumulate during cycling loading on composite materials, the AE waveforms of damage mechanisms could be distorted. This eventuality is studied with a quantification of its impact on the AE features. The idea is to assess the distortion of acoustic signatures of damages during fatigue tests. An acoustic signature of a particular damage could be simulated using an artificial AE source. While damages progress in the material, a hit is generated by an artificial acoustic source (representing an emerging or developing defect) at several instants during the test and waveforms picking is performed using an AE sensor. The evolution of these measured waveforms is then evaluated. It should be pointed out that the artificial AE sources are created in undamaged areas of the material and the propagation of their transmitted AE hits through a cumulative damaged area is studied here. The zone of the material in the vicinity of the artificial AE sources could be affected by microscopic fractures during the tests, however this cannot be visually verified.

\subsection{Mechanical testing}

The tested material is a $\pm 45^{\circ}$ biaxial carbon fiber-reinforced epoxy resin polymer, composed of eight plies stitched with a textured polyester yarn. The specimens have the dimensions $250 \times 25 \times 3.5 \mathrm{~mm}$. In order to determine the composite material properties, several quasi-static (QS) tensile tests were performed on identical healthy specimens at a speed of $2 \mathrm{~mm} / \mathrm{min}$. Other specimens were also subjected to tensile-tensile fatigue tests at different loading levels ranging from $50 \%$ to $70 \%$ of the ultimate tensile strength (UTS). The profile of solicitation is sinusoidal with a frequency of $5 \mathrm{~Hz}$ and a stress ratio $R=0.1$ (where $R=\sigma_{\min } / \sigma_{\max }$ ). In order to assess the damage development during the tests, two extensometers were mounted to measure the longitudinal and transverse strains (gauge lengths equal to $50 \mathrm{~mm}$ and $12.5 \mathrm{~mm}$, respectively). The loading was interrupted at regular time intervals during the tests with $57 \%$ and $70 \%$ UTS loading levels, so as to allow generating AE waveforms at different health states of the material. 


\subsection{Fatigue degradation and modelling}

Stiffness degradation has been widely considered by researchers for fatigue damage modelling and life predictions $[4,57]$. Concerning composites exhibiting significant nonlinear tensile behavior (due to fiber rotation, plastic deformation of matrix, etc.), the evolution of the dynamic stiffness does not often provide accurate means to assess the damage development. Petermann and Schulte [58] have reported that the mean strain is more meaningful for describing the fatigue degradation process. Other researchers [59-61] have also employed the mean strain in damage accumulation modelling instead of the young modulus, since it provides indications about the three stages of damage development. The mean strain is determined from the maximum and minimum strains for a particular loading cycle $N$ such as

$$
\epsilon_{\text {mean }}(N)=\frac{\epsilon_{\max }(N)+\epsilon_{\min }(N)}{2} .
$$

The damage development can be assessed experimentally using a damage index $D$ expressed as a function of the mean strain $\epsilon_{\text {mean }}(N)$ as follows:

$$
D(N)=\frac{\epsilon_{\text {mean }}(N)-\epsilon_{\text {mean }}(o)}{\epsilon_{\text {mean }}\left(N_{f}\right)-\epsilon_{\text {mean }}(o)},
$$

where $\epsilon_{\text {mean }}(o)$ and $\epsilon_{\text {mean }}\left(N_{f}\right)$ are the initial and final mean strains respectively, and $N_{f}$ is the number of cycles to failure at the corresponding applied loading level. The variable $D$ is employed in the phenomenological models that characterize the residual rigidity and fatigue life of materials in terms of macroscopically observable properties $[62,63]$. Several models have been developed to predict the remaining life of composite structures [64-66]. In this study, the analytical damage model introduced by Mao and Mahadevan [67] is used. It consists in a normalized accumulated damage model for describing the damage growth during all three stages of load cycling exhibited by the material. This model has the following form:

$$
D(N)=q\left(\frac{N}{N_{f}}\right)^{m_{1}}+(1-q)\left(\frac{N}{N_{f}}\right)^{m_{2}},
$$

where $q, m_{1}$ and $m_{2}$ are parameters dependent on the material and the applied stress level. They can be determined by fitting the analytical damage index $D$ in Eq. 3 to the experimental one represented using Eq. 2.

\subsection{Creation of artificial AE sources}

During a cyclic loading test, various types of damages appear with different AE signatures. Some hits detected by the sensor during the test are shown in Fig. 2. The aim was to reproduce an AE source able to generate acoustic signals with similar characteristics as the real detected AE hits at the sensor level. Artificial AE sources were hence used in order to generate acoustic signals in the material with different shapes representing some typical AE hits at the sensor level. The signals were generated at several instants during the fatigue life of the material starting with a healthy specimen until its total failure. The acoustic sources were reproduced by PLBs and an ultrasonic transducer used as a transmitter, according to Fig. 3. In order to verify the reproducibility of the generated 
signals, five waveforms were emitted successively after each interruption of the loading throughout the test. The hydraulic system of the testing machine was stopped in order to avoid any perturbation caused by the background noise. It should be mentioned that it is not a matter here of assigning the acoustic signatures to the damage mechanisms, but just to generate acoustic waveforms with similar characteristics (time and frequency shapes, amplitudes and durations) as the real acoustic signatures of damages in composites. The artificial AE sources were applied near the upper clamping jaw of the testing machine, far from the expected damaged area of the specimen. The zone of application could be likely partially damaged, however this was not visually confirmed.

\subsubsection{Waveforms generation using Pencil Lead Breaks}

The PLBs were applied on three different boundaries of the specimen: two opposite surfaces (Faces 1 and 2) and the edge (Face 3). This allows generating hits with different shapes representing out-ofplane and in-plane AE sources, which could be close to the real AE sources. Indeed, a PLB applied on the top surface of a composite plate generates out-of-plane AE sources; whereas, if it is applied on the edge surface of the plate, in-plane AE sources are expected [48-50, 52]. For the three considered application surfaces, the PLBs were performed almost at the same distance from the AE sensor (see Fig. 3(a)).

\subsubsection{Waveforms generation using an ultrasonic transducer}

The transducer used as a transmitter was mounted on "Face 1" in an undamaged area throughout the tests, according to Fig. 3(b). The input signal of the transducer was created using a waveform generator (Tabor Electronics 5064, $100 \mathrm{MS} / \mathrm{s}$ ) and a power amplifier (Tabor Electronics $9100 \mathrm{~A}$, with a fixed gain of 50). It was an impulse-like signal optimized in terms of its shape, duration and amplitude to obtain transient bursts at the sensor level similar to those generated by a PLB. The input signal is shown in Fig. 4(a) at the output of the waveform generator and in Fig. 4(b) at the output of the power amplifier. The transducer used as a transmitter is a Micro 80-type sensor with an operating frequency-range of [200-900 kHz] and a resonant frequency of $325 \mathrm{kHz}$.

\subsection{Signal acquisition}

The signal acquisition is ensured by an AE system with the characteristics mentioned in Table 1. The AE sensor was similar as the transducer used as a transmitter. Both were provided by Mistras Group. An example of the waveforms detected by the AE sensor when the ultrasonic transducer was used as an artificial AE source is shown in Fig. 4(c). Some samples of hits detected after performing PLBs on the top surface and the edge of the specimen are shown in Fig. 5. The detected waveforms, when using both artificial $\mathrm{AE}$ sources, are quite similar in terms of shape, amplitude and duration to those detected with real damages (see Fig. 2). These artificial AE sources also allow generating waveforms with diversified characteristics in time and frequency domains, as shown subsequently. 


\section{Experimental procedure and results}

In the following, the composite material used in this study is firstly characterized to offer complete information about its tensile and fatigue behaviors. The material properties are determined after QS monotonic tests. Fatigue cycling tests at different loading levels are carried out in order to emphasize the validity of the subsequent results of wave distortions for any loading level.

\subsection{Monotonic-tensile and fatigue behaviors of the composite material}

Figure 6 shows the stress over the longitudinal and transverse strains measured during the monotonic tensile tests for four identical specimens. The tensile response consists in an elastic-ductile behavior with a quasi-linear response up to a yield point at 55-65 MPa, followed by an inflexion of the tensile curve above this point up to failure. The mean longitudinal strain to failure is approximately $16.9 \%$ (Table 2). This non-linear response can be related to the time-dependent behavior and plastic strains of the polymeric constituents, and also to some damage mechanisms such as fiber matrix debonding and rotation of fiber bundles mainly due to necking. These damages and bundles reorientation as a function of longitudinal strain can be observed during the tests (Fig. 1(a), right) and using fractography.

The fatigue cycling tests at different loading levels allowed the Wöhler curve to be plotted (see Fig. 7). It shows the maximum applied stress over the number of cycles to failure. The square markers (at 35\%, 40\%, 57\% and 70\% UTS) indicate the tests performed continuously until the specimen's total failure (except for $35 \%$ and $40 \%$ where the tests were stopped before the rupture of the specimens). The triangle markers (at 57\% and 70\% UTS) are related to those with multiple interruptions during the fatigue test in order to allow generating acoustic waves. Measurements of the temperature variation at the surface of the tested specimen (caused by cyclic loading) using infrared thermography have shown a change in the heat dissipation when the fatigue test was interrupted.

Figure 8(a) shows the mean longitudinal strains obtained with different loading levels over the number of cycles. A comparison between the damage indexes experimentally determined using the mean strain-based method of Petermann and Schulte [58] and those predicted using the analytical model of Mao and Mahadevan [67] over the cycle ratio is presented in Fig. 8(b). The damage index curves are described by three stages: the first one is characterized by a rapid stiffness degradation; followed by a gradual decrease in stiffness throughout the majority of the fatigue life; and finally the damage accumulation causes a significant decrease in stiffness prior to failure.

Hereafter, the test performed with an applied stress level of $70 \%$ UTS is taken as an example to conduct the study. Under this loading level, the material failed after 4144 cycles with 17 interruptions.

\subsection{Effect of cumulated damages on the PLB-generated waveforms}

Figure 9 shows the detected waveforms and their corresponding scalograms at three different damage levels, when using a PLB as AE source on "Face 1". It can be remarked that the signals' shape is distorted under the effect of cumulated damage. Indeed, the discontinuities emerged in the material, 
and caused by the initiation and development of defects, engender a wave dispersion which modifies the waveforms. The scalograms indicate an evolution in the frequency domain of these waveforms with the damage level. The emergent defects can produce a mode conversion: Other wave propagation modes appear, such as flexural modes, with different frequency spectra, as can be observed in Fig. 9 . It should be mentioned here that the waveforms' distortions could be partly caused by a distortion of the artificial AE source. In fact, the zone of application of the PLB could be microscopically or partially damaged. That way, the generated waveform would be already distorted before propagating in the damaged area of the material. When an AE source is simulated using a PLB on "Face 2", similar results as previously are obtained. For the sake of convenience, the corresponding results are not presented.

When applying PLBs on the edge of the plate ("Face 3"), the detected waveforms are quite different from those previously treated, as we can notice in Fig. 10. The footprint of high-frequency modes (in the range of $[100-500 \mathrm{kHz}])$ is more present here, when an in-plane AE source is simulated, comparing to the case of an out-of-plane AE source. Gradually, these modes are damped with the damage development until a total extinction in the last measure before failure.

An important impact of the cumulated damage on the AE features is observed. Figures 11 and 12 show some selected features where their evolution depending on the damage index can be noticed. The cumulated damage during fatigue cycling clearly affects the AE features in both "Face 1" and "Face 3" cases. The variability of the features is relatively high, since it would be influenced by the various parameters affecting the breaking of the pencil-leads, as mentioned in the introduction. Besides that, some important remarks can be drawn by comparing the AE-features obtained from both material surfaces. In the case of "Face 1", some energy-related AE-features, like PAC-Energy, duration and amplitude are larger than those obtained with "Face 3". Out-of plane waves are found to be more energetic than in-plane waves. In contrast, frequency centroid and peak frequency are higher in the case of "Face 3". In-plane waves are thus characterized by high-frequency contents comparing to out-of-plane waves, which was already remarked in the scalograms.

\subsection{Effect of cumulated damages on the transducer-generated waveforms}

When using an ultrasonic transducer as AE source on "Face 1", the detected waveforms at three different damage levels and their corresponding scalograms are shown in Fig. 13. The shape of the AE signals is noticeably distorted, and the scalograms exhibit an evolution in their frequency spectra under the effect of cumulated damage. As mentioned previously, a part of these distortions might be engendered by an eventual degradation of the material in the vicinity of the artificial AE source. We can point out that the signals are characterized by relatively high frequencies (above $200 \mathrm{kHz}$ ). They are then greatly weakened with damage accumulation and toggle to lower frequencies (as for the PLB case). The AE-features computed from the detected hits are evolving during the damage development, as shown in Fig. 14. Their variability is much lower than that obtained using PLB. The waveforms emitted by the transducer are almost identical since their generation is completely mastered. Thus, 
it can be concluded that the transducer used as a transmitter has a better reproducibility than the PLB. It allows an accurate description of the wave distortion and the evolution of the AE features as a function of damage level.

The behavior of some AE features is difficult to predict, mainly with a non-monotonic evolution. Hence, their tendencies could not be faithfully monitored during the fatigue life of the material, with the aim of compensating the effect of damage accumulation on the AE features.

\subsection{Evolution of the AE-features diagrams with damage development}

The pattern recognition approaches are used to distinguish the possible natural clusters/classes associated to the damage mechanisms. Figure 15 shows different representations, in the AE features space, of the data-point associated to the same hit detected after simulating an AE source by an ultrasonic transducer during the damage accumulation. It can be remarked that the evolving position of this hit covers a wide area, which could considerably affect the identification of the natural clusters/classes. A decrease of more than $30 \mathrm{~dB}$ in amplitude and about $1.5 \mathrm{~ms}$ are observed when moving from the data-point 1 (no damage) to the data-point 17 (total failure). A great change in the frequency spectrum can also be remarked: the weighted peak frequency undergoes a drop of about $150 \mathrm{kHz}$ during the fatigue life of the material.

Therefore, it would be of interest to integrate consideration of these waveforms' evolutions in the data clustering approaches. Our idea is to use unsupervised or semi-supervised clustering approaches that are able to adapt the form of the clusters along different directions in the AE features space, in order to follow and consider the features evolution with damage accumulation. This can be achieved using specific algorithms that are not based on compactness and circularity of clusters in features space. Generally, clustering algorithms applied on AE signals are based on the Euclidean distance, which suppose cluster compactness and circularity in the original feature space, such as K-means, fuzzy C-means and a variant of Self-Organizing Maps. Some validity indices used to estimate the number of clusters are also based on this particular distance. The validity of this hypothesis can be clearly questioned in tests, such the one presented in our study, in which damages cumulated in the composite and the associated discontinuities, induces a distortion over time of the transients propagating through the material. The capacity of some unsupervised techniques that we have developed recently will be illustrated in a forthcoming paper. Using such approaches, even if the clusters are initially compact, their prototypes can move in the feature space and their shapes may change as a function of the damage level in the composite. These techniques are partially described in previous papers [11, 12]. In order to enhance data-driven phenomenological physics-models with better prediction capabilities, it is thus of paramount importance to develop specific clustering algorithms dedicated to AE signals originating from composite materials. These signals are unevenly time-spaced and consist in transients ordered chronologically with increasingly emergent damage mechanisms. In addition, these transients are propagating in a non-stationary media during the test. The amount of uncertainty on the characteristics of acoustic sources deduced from those statistical models should also be quantified, since 
results are highly dependent on multifarious parameters and unknown factors.

\section{Conclusions}

This study focused on the influence of damage accumulation during cyclic fatigue loading on the acoustic signatures of fracture mechanisms in carbon/epoxy composites. Specifically, the propagation through a cumulatively damaged area of a specific acoustic signature created in an undamaged area was assessed. Reproducible artificial AE sources were created by PLBs and an ultrasonic transducer used as a transmitter in undamaged areas on different surfaces of the material in order to generate various damage-like acoustic signatures. The waveforms detected at the sensor level were characterized as similar in time and frequency domains to those obtained with real local fracture mechanisms in composites. During the fatigue life of the material, identical AE hits were generated using the artificial sources at different instants. At each time, the $\mathrm{AE}$ waveforms were measured at the same location by an $\mathrm{AE}$ sensor. It was remarked that the waveforms issued from both artificial $\mathrm{AE}$ sources were clearly distorted in the time and frequency domains due to the damage accumulation. The AE features exhibited a relatively important evolution as a function of damage level. The behavior of some AEfeatures was sometimes difficult to predict, since their evolutions were non-stationary during the fatigue life of the material. Although the noticed distortions were patently engendered by the propagation of the $\mathrm{AE}$ waveforms through a damaged area, a distortion at the very $\mathrm{AE}$ source can be at the origin of a part of the waveform's distortions. An eventual damage in the vicinity of the AE source can contribute to the distortions. The case of an $\mathrm{AE}$ source generated in a damaged area deserves also to be investigated. This issue is being studied by the authors and will be addressed in a future work.

Even if the conclusions drawn in this study were obtained for a particular stress level, they can be generalized for any loading level since the evolutions of the damage index as a function of the cycle ratio are similar.

The major contribution of this paper was to underline - on the basis of one representative test that the AE features evolution due to damage cumulated during mechanical loading can be significant, and clearly deserves to be taken into account in pattern recognition techniques. It should be mentioned that it was not a matter, in this work, to establish a model able to predict the features evolution as a function of damage, but to give guidance to improve the pattern recognition algorithms by using specific unsupervised or semi-supervised clustering approaches able to adapt the shapes of clusters along several directions in the features spaces during the progression of damage. This kind of approaches is being developed by the authors and will be addressed in a future study.

\section{Acknowledgments}

This work was supported by the Laboratory of Excellence ACTION through the program "Investments for the Future" managed by the National Agency for Research (references ANR-11-LABX-01-01) 
and by BPI France and the Franche-Comté Region through the project "Smart Composites". The authors would like to thank the MEMS team belonging to the department of Applied Mechanics for providing instruments for the waveform generation and for its technical assistance.

\section{Appendix}

The AE-features studied in this paper are defined below as implemented in the used algorithm [56].

- Counts: The number of times the AE signal $s(t)$, of length $L$, exceeds the preset threshold $T H$ :

$$
\text { Counts }=\sum_{t=1}^{L} \mathbb{I}_{s(t) \geq T H},
$$

where $\mathbb{I}_{x}$ is an indicator function equal to 1 if the condition $x$ is true.

- Duration $[\mu s]$ : The time between the start and the end of the AE hit:

$$
\text { Duration }=L \cdot \Delta t \text {. }
$$

where $\Delta t$ is a sampling period.

- Amplitude $[d B]$ : A logarithmic measure of the maximum voltage of the AE hit expressed as:

$$
d B_{A E}=20 \log _{10}\left(\frac{A_{\max }}{A_{0}}\right)-P G,
$$

where $A_{\max }$ is the peak amplitude of the $\mathrm{AE}$ hit, $A_{0}$ is a reference amplitude equal to $1 \mu V$ at the sensor (before amplification), and $P G$ is the preamplifier gain.

- PAC-Energy $\left(E_{P A C}\right)[\mu V s]$ : PAC-Energy is the sum of the signal envelope over the duration and converted into counts at $100 \mathrm{kHz} / \mathrm{V}$ :

$$
E_{P A C}=\sum_{t}|H[s(t)]| \cdot \Delta t \cdot 100 \cdot 10^{6},
$$

where $H$ is the envelope - computed by the Hilbert Transform - of the signal above the threshold.

- Frequency Centroid $\left(f_{c t r}\right)[k H z]$ : It is computed from the FFT magnitude as a weighted average of the FFT magnitude:

$$
f_{c t r}=\frac{\sum_{f} M_{F F T}(f) \cdot f}{\sum_{f} M_{F F T}(f)}
$$

where $M_{F F T}(f)$ is the FFT magnitude at a frequency $f$. Both the lower and the upper bounds of the sum may be adapted according to the application.

- Peak Frequency $\left(f_{\text {peak }}\right)[k H z]$ : It is the peak of the power spectrum of the AE hit:

$$
f_{\text {peak }}=\underset{f}{\arg \max } M_{F F T}(f) .
$$


- Partial Power features $\left(P P_{k}\right)[\%]$ : They are derived from the power spectrum of the AE hit and reported as a percentage in a given user-defined frequency band $I_{k}=\left[f_{1}^{k}, f_{2}^{k}\right]$ :

$$
P P_{k}=100 \cdot \frac{\sum_{f \in I_{k}} P S(f)}{\sum_{g \in \cup_{k} I_{k}} P S(g)},
$$

where $P S$ is the value of the power spectrum and $k$ is ranging from 1 to the total number of frequency bands.

Partial power 1: $f_{1}=0 \mathrm{kHz} ; f_{2}=150 \mathrm{kHz}$.

Partial power 2: $f_{1}=150 \mathrm{kHz} ; f_{2}=300 \mathrm{kHz}$.

Partial power 3: $f_{1}=300 \mathrm{kHz} ; f_{2}=500 \mathrm{kHz}$.

Partial power 4: $f_{1}=500 \mathrm{kHz} ; f_{2}=1 \mathrm{MHz}$.

- Weighted Peak Frequency (WPF) $[k H z]$ : It is computed from the frequency centroid and peak frequency as follows:

$$
W P F=\sqrt{f_{\text {peak }} \cdot f_{c t r}}
$$

\section{References}

[1] J.-M. Berthelot, Composite materials: mechanical behavior and structural analysis, Springer, 1999.

[2] D. B. Miracle, S. L. Donaldson, Introduction to composites, Materials Park, OH: ASM International, 2001. (2001) 3-17.

[3] Y. Mouton, Organic materials in civil engineering, Vol. 95, John Wiley \& Sons, 2010.

[4] B. Harris, Fatigue and accumulation of damage in reinforced plastics, Composites 8 (4) (1977) 214-220.

[5] J. Berthelot, J. Rhazi, Acoustic emission in carbon fibre composites, Composites Science and Technology 37 (4) (1990) $411-428$.

[6] R. Unnthorsson, T. Runarsson, M. Jonsson, Acoustic emission based fatigue failure criterion for CFRP, International Journal of Fatigue 30 (1) (2008) 11-20.

[7] M. J. Eaton, R. Pullin, K. M. Holford, Acoustic emission source location in composite materials using Delta T Mapping, Composites Part A: Applied Science and Manufacturing 43 (6) (2012) 856-863.

[8] R. D. Averett, M. L. Realff, K. I. Jacob, Comparative post fatigue residual property predictions of reinforced and unreinforced poly (ethylene terephthalate) fibers using artificial neural networks, Composites Part A: Applied Science and Manufacturing 41 (3) (2010) 331-344. 
[9] E. Maillet, N. Godin, M. RMili, P. Reynaud, G. Fantozzi, J. Lamon, Damage monitoring and identification in $\mathrm{SiC} / \mathrm{SiC}$ minicomposites using combined acousto-ultrasonics and acoustic emission, Composites Part A: Applied Science and Manufacturing 57 (2014) 8-15.

[10] M. Sause, T. Müller, A. Horoschenkoff, S. Horn, Quantification of failure mechanisms in mode-I loading of fiber reinforced plastics utilizing acoustic emission analysis, Composites Science and Technology 72 (2) (2012) 167-174.

[11] D. Doan, E. Ramasso, V. Placet, S. Zhang, L. Boubakar, N. Zerhouni, An unsupervised pattern recognition approach for $\mathrm{AE}$ data originating from fatigue tests on polymer-composite materials, Mechanical Systems and Signal Processing 6465 (2015) $465-478$.

[12] E. Ramasso, V. Placet, M. L. Boubakar, Unsupervised consensus clustering of acoustic emission time-series for robust damage sequence estimation in composites, Instrumentation and Measurement, IEEE Transactions on 64 (12) (2015) 3297-3307.

[13] E. Ramasso, V. Placet, R. Gouriveau, L. Boubakar, N. Zerhouni, et al., Health assessment of composite structures in unconstrained environments using partially supervised pattern recognition tools., in: Prognostics and Health Management Society. Annual Conference of the Prognostics and Health Management Society, Hyatt Regency Minneapolis, Minnesota: United States, 2012, pp. $1-11$.

[14] Y. Higo, H. Inaba, The general problems of AE sensors, in: Acoustic Emission: Current practice and future directions, Wolfgang Sachse, Kusuo Yamaguchi, James Roge Edition, ASTM, 1991, pp. 7-24.

[15] M. Barbezat, A. Brunner, P. Flüeler, C. Huber, X. Kornmann, Acoustic emission sensor properties of active fibre composite elements compared with commercial acoustic emission sensors, Sensors and Actuators A: physical 114 (1) (2004) 13-20.

[16] M. G. Sause, M. A. Hamstad, S. Horn, Finite element modeling of conical acoustic emission sensors and corresponding experiments, Sensors and Actuators A: Physical 184 (2012) 64-71.

[17] P. Theobald, B. Zeqiri, J. Avison, Couplants and their influence on AE sensor sensitivity, Journal of Acoustic Emission 26 (2008) 91-97.

[18] D. Geisse, Improving the coupling reproducibility of piezoelectric transducers, Journal of Acoustic Emission 12 (3-4) (1994) 171-176.

[19] J. J. Scholey, P. D. Wilcox, M. R. Wisnom, M. I. Friswell, Design considerations for the acoustic emission testing of large composite specimens, in: SPIE Smart Structures and Materials \& Nondestructive Evaluation and Health Monitoring, International Society for Optics and Photonics, 2009, p. 729405 . 
[20] D. Aggelis, T. Matikas, Effect of plate wave dispersion on the acoustic emission parameters in metals, Computers \& Structures 98 (2012) 17-22.

[21] D. Aggelis, T. Shiotani, A. Papacharalampopoulos, D. Polyzos, The influence of propagation path on elastic waves as measured by acoustic emission parameters, Structural Health Monitoring (2011) 359-366.

[22] W. Prosser, The propagation characteristics of the plate modes of acoustic emission waves in thin aluminum plates and thin graphite/epoxy composite plates and tubes, Ph.D. thesis, The Johns Hopkins University, Baltimore, Maryland (1991).

[23] J. Verbis, S. Kattis, S. Tsinopoulos, D. Polyzos, Wave dispersion and attenuation in fiber composites, Computational Mechanics 27 (3) (2001) 244-252.

[24] M. Lowe, G. Neau, M. Deschamps, Properties of guided waves in composite plates, and implications for NDE, in: Quantitative Nondestructive Evaluation, American Institute of Physics, 2004, pp. 214-221.

[25] K. Asamene, L. Hudson, M. Sundaresan, Influence of attenuation on acoustic emission signals in carbon fiber reinforced polymer panels, Ultrasonics 59 (2015) 86-93.

[26] J. J. Scholey, P. D. Wilcox, M. R. Wisnom, M. I. Friswell, Quantitative experimental measurements of matrix cracking and delamination using acoustic emission, Composites Part A: Applied Science and Manufacturing 41 (5) (2010) 612-623.

[27] M. G. Sause, S. Horn, Influence of internal discontinuities on ultrasonic signal propagation in carbon fiber reinforced plastics, in: 30th European Conference on Acoustic Emission Testing and 7th International Conference on Acoustic Emission, 2012.

[28] A. Carpinteri, G. Lacidogna, F. Accornero, A. Mpalaskas, T. Matikas, D. Aggelis, Influence of damage in the acoustic emission parameters, Cement and Concrete Composites 44 (2013) 9-16.

[29] S. Al-Dossary, R. Hamzah, D. Mba, Observations of changes in acoustic emission waveform for varying seeded defect sizes in a rolling element bearing, Applied Acoustics 70 (1) (2009) 58-81.

[30] A. Vary, The Acousto-Ultrasonic approach, in: Acousto-Ultrasonics, Theory and Applications, J. C. Duke Jr., ed., Plenum Press, 1988.

[31] M. Kharrat, L. Gaillet, Non-destructive evaluation of anchorage zones by ultrasonics techniques, Ultrasonics 61 (2015) 52-61.

[32] A. Vary, K. J. Bowles, An ultrasonic-acoustic technique for nondestructive evaluation of fiber composite quality, Polymer Engineering \& Science 19 (5) (1979) 373-376.

[33] A. Vary, Acousto-Ultrasonics, in: J. Summerscales (Ed.), Nondestructive Testing of fibrereinforced plastics composites, Elsevier Science Publishers, 1990. 
[34] R. Russell-Floyd, M. Phillips, A critical assessment of acousto-ultrasonics as a method of nondestructive examination for carbon-fibre-reinforced thermoplastic laminates, NDT international 21 (4) (1988) 247-257.

[35] O.-Y. Kwon, S.-H. Lee, Acousto-ultrasonic evaluation of adhesively bonded CFRP-aluminum joints, NDT \& E International 32 (3) (1999) 153-160.

[36] T. Peng, A. Saxena, K. Goebel, Y. Xiang, Y. Liu, Integrated experimental and numerical investigation for fatigue damage diagnosis in composite plates, Structural Health Monitoring 13 (5) (2014) 537-547.

[37] A. Maslouhi, H. Saadaoui, S. Bland, C. Roy, Acousto-ultrasonic signal classification to evaluate high temperature degradation in composites, Journal of Acoustic Emission 12 (1-2) (1994) 45-54.

[38] T. Loutas, V. Kostopoulos, Health monitoring of carbon/carbon, woven reinforced composites. damage assessment by using advanced signal processing techniques. part i: Acoustic emission monitoring and damage mechanisms evolution, Composites science and technology 69 (2) (2009) 265-272.

[39] T. Loutas, V. Kostopoulos, Health monitoring of carbon/carbon, woven reinforced composites: Damage assessment by using advanced signal processing techniques. part ii: Acoustoultrasonics monitoring of damage development, Composites Science and Technology 69 (2) (2009) $273-283$.

[40] ASTM E976-10, Standard Guide for Determining the Reproducibility of Acoustic Emission Sensor Response, ASTM International, west Conshohocken, PA, 2010.

[41] S. McBride, T. Hutchison, Helium gas jet spectral calibration of acoustic emission transducers and systems, Canadian Journal of Physics 54 (17) (1976) 1824-1830.

[42] T. Hutchison, S. McBride, Excitation and spectral calibration of acoustic emission systems, US 4064735 A (1977).

[43] A. Prateepasen, Y. Au, B. Jones, Comparison of artificial acoustic emission sources as calibration sources for tool wear monitoring in single-point machining, Journal of Acoustic Emission 18 (2000) 196.

[44] C. Scruby, H. Wadley, R. Dewhurst, S. Palmer, D. Hutchins, A laser-generated standard acoustic emission source, Materials Evaluation 39 (1981) 1250-1254.

[45] D. Hutchins, R. Dewhurst, S. Palmer, C. Scruby, Laser generation as a standard acoustic source in metals, Applied Physics Letters 38 (9) (1981) 677-679.

[46] S. Davies, C. Edwards, G. Taylor, S. B. Palmer, Laser-generated ultrasound: its properties, mechanisms and multifarious applications, Journal of Physics D: Applied Physics 26 (3) (1993) 329. 
[47] N. Hsu, F. Breckenridge, Characterization and calibration of acoustic emission sensors, Materials Evaluation 39 (1) (1981) 60-68.

[48] J. Gary, M. A. Hamstad, On the far-field structure of waves generated by a pencil lead break on a thin plate, Journal of Acoustic Emission 12 (3-4) (1994) 157-170.

[49] M. Hamstad, Acoustic emission signals generated by monopole (pencil lead break) versus dipole sources: finite element modeling and experiments, Journal of Acoustic Emission 25 (2007) 92-106.

[50] W. Prosser, M. Gorman, Accurate simulation of acoustic emission sources in composite plates, in: Proceedings of the 1994 ASNT Spring Conference, Citeseer, 1994.

[51] A. Gupta, J. C. Duke Jr, Detecting damage transitions in laminated composites using simulated acoustic emission, in: 13th International Symposium on Nondestructive Characterization of Materials (NDCM-XIII) , 20-24 May 2013, Le Mans, France.

[52] M. R. Gorman, W. H. Prosser, AE source orientation by plate wave analysis, Journal of Acoustic Emission 9 (4) (1991) 283-288.

[53] T. Boczar, M. Lorenc, Determining the repeatability of acoustic emission generated by the HsuNielsen calibrating source, Molecular and Quantum Acoustics 25 (2004) 177-192.

[54] M. G. Sause, Investigation of pencil-lead breaks as acoustic emission sources, Journal of Acoustic Emission 29 (2011) 184-196.

[55] H. Dunegan, An alternative to pencil lead breaks for simulation of acoustic emission signal sources, The DECI report.

[56] M. Kharrat, E. Ramasso, V. Placet, M. Boubakar, A signal processing approach for enhanced acoustic emission data analysis in high activity systems: Application to organic matrix composites, Mechanical Systems and Signal Processing 70 (2016) 1038-1055.

[57] A. Wharmby, F. Ellyin, J. Wolodko, Observations on damage development in fibre reinforced polymer laminates under cyclic loading, International Journal of Fatigue 25 (5) (2003) 437-446.

[58] J. Petermann, K. Schulte, The effects of creep and fatigue stress ratio on the long-term behaviour of angle-ply CFRP, Composite Structures 57 (1) (2002) 205-210.

[59] A. Plumtree, M. Melo, J. Dahl, Damage evolution in a $[ \pm 45]_{2 S}$ CFRP laminate under block loading conditions, International Journal of Fatigue 32 (1) (2010) 139-145.

[60] J. Montesano, M. Selezneva, Z. Fawaz, C. Poon, K. Behdinan, Elevated temperature off-axis fatigue behavior of an eight-harness satin woven carbon-fiber/bismaleimide laminate, Composites Part A: Applied Science and Manufacturing 43 (9) (2012) 1454-1466. 
[61] W. Albouy, B. Vieille, L. Taleb, Influence of matrix ductility on the high-temperature fatigue behavior of off-axis woven-ply thermoplastic and thermoset laminates, International Journal of Fatigue 63 (2014) 85-96.

[62] J. Degrieck, W. Van Paepegem, Fatigue damage modeling of fibre-reinforced composite materials: Review, Applied Mechanics Reviews 54 (4) (2001) 279-300.

[63] R. Böhm, M. Gude, W. Hufenbach, A phenomenologically based damage model for textile composites with crimped reinforcement, Composites Science and Technology 70 (1) (2010) 81-87.

[64] T. Adam, R. F. Dickson, C. J. Jones, H. Reiter, B. Harris, A power law fatigue damage model for fibre-reinforced plastic laminates, Proceedings of the Institution of Mechanical Engineers, Part C: Journal of Mechanical Engineering Science 200 (3) (1986) 155-166.

[65] H. G. Halverson, W. A. Curtin, K. L. Reifsnider, Fatigue life of individual composite specimens based on intrinsic fatigue behavior, International Journal of Fatigue 19 (5) (1997) 369-377.

[66] S. Subramanian, K. Reifsnider, W. Stinchcomb, A cumulative damage model to predict the fatigue life of composite laminates including the effect of a fibre-matrix interphase, International Journal of Fatigue 17 (5) (1995) 343-351.

[67] H. Mao, S. Mahadevan, Fatigue damage modelling of composite materials, Composite Structures 58 (4) (2002) 405-410. 


\section{List of Figures}

1 Purpose of the study. (a) The raised issue: potential evolution of the acoustic signatures of local fracture mechanisms during cyclic loading; and (b) the proposed methodology to quantify the AE wave distortion under the effect of damage accumulation. . . . . . . 23

2 Some AE signatures of different real damages appeared during a cyclic fatigue test performed on the composite. Artificial AE sources are used to reproduce damage-like AE signatures with similar characteristics as the real damage-related signatures. . . . . 24

3 Test configuration for generating AE damage-like signals using artificial sources. . . . . 25

4 Artificial acoustic source created by an ultrasonic transducer used as a transmitter. . . . 26

5 Pencil Lead Break signals detected at the AE sensor level mounted on "Face 1" of a healthy composite material. . . . . . . . . . . . . . . . . . 27

6 Stress-strain curves obtained from the QS monotonic tests performed on four identical composite specimens, where $\epsilon_{l}$ and $\epsilon_{t}$ are the longitudinal and transverse strains respectively. Each color represents a test performed on one specimen. . . . . . . . . . . 28

7 Wöhler curve determined after fatigue cycling tests performed on the composite material at different loading levels at a frequency of $5 \mathrm{~Hz}$ and a stress ratio $R=0.1$. Continuous loading: 35\%, 40\%, 57\% and 70\% UTS; with interruptions: $57 \%$ and $70 \%$ UTS. . . . . 29

8 Damage evolution with cyclic loading: (a) mean longitudinal strain for different loading levels over the number of cycles, (b) experimental damage index and numerical prediction using the Mao-and-Mahadevan's damage model.

9 Waveforms distortion with cumulated damage when using a PLB on "Face 1" as AE

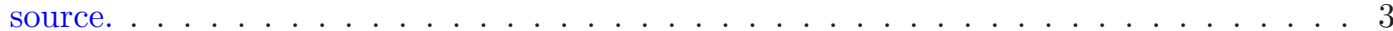

10 Waveforms distortion with cumulated damage when using a PLB on "Face 3" as AE

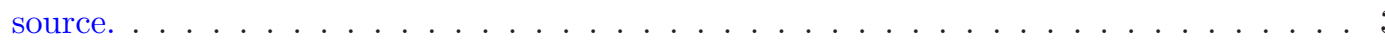

11 Evolution of the AE-features with cumulated damage when using a PLB on "Face 1"

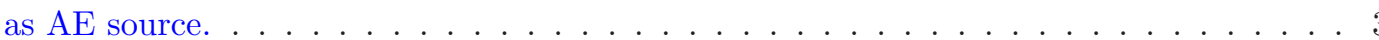

12 Evolution of the AE-features with cumulated damage when using a PLB on "Face 3"

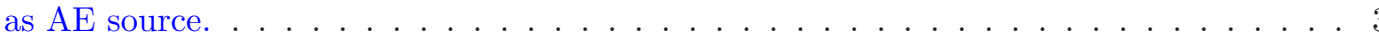

13 Waveforms distortion with cumulated damage when using an ultrasonic transducer as AE source.

14 Evolution of the AE-features with cumulated damage when using an ultrasonic transducer as AE source. . . . . . . . . . . . . . . . . . . . . 36

15 Modification of the AE-features diagrams of a detected hit during the damage accumulation. AE source reproduced using an ultrasonic transducer. Data point 1 represents $D=0$, and data point 17 represents $D=1$ 


\section{List of Tables}

1 AE system setup parameters. . . . . . . . . . . . . . . . . . . . 21

2 Average material properties determined after quasi-static tensile tests. . . . . . . . . . 22 
Table 1: AE system setup parameters.

\begin{tabular}{ll}
\hline System parameters & Defined values \\
\hline Threshold & $40 \mathrm{~dB}$ \\
Pre-Amplifier & $20 \mathrm{~dB}$ \\
Analog Filter & $20 \mathrm{kHz}-1 \mathrm{MHz}$ \\
Sampling Rate & $5 \mathrm{MS} / \mathrm{s}$ \\
PDT & $60 \mu \mathrm{s}$ \\
HDT & $120 \mu \mathrm{s}$ \\
HLT & $300 \mu \mathrm{s}$ \\
Max. Duration & $200 \mathrm{~ms}$ \\
\hline
\end{tabular}


Table 2: Average material properties determined after quasi-static tensile tests.

\begin{tabular}{ll}
\hline Material properties & Average values \\
\hline Ultimate tensile strength & $100 \pm 6.2 \mathrm{MPa}$ \\
Longitudinal strain to fracture & $16.9 \pm 3.5 \%$ \\
Young modulus & $11.1 \pm 1.4 \mathrm{GPa}$ \\
\hline
\end{tabular}




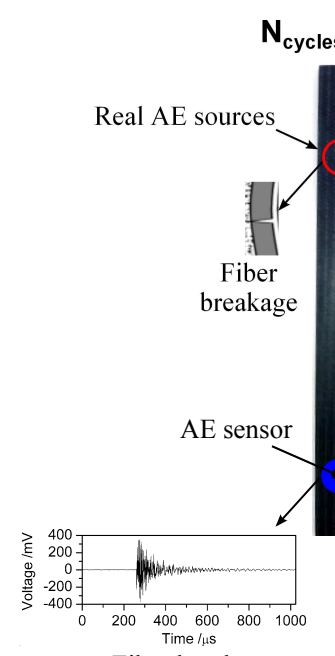

Fiber breakage

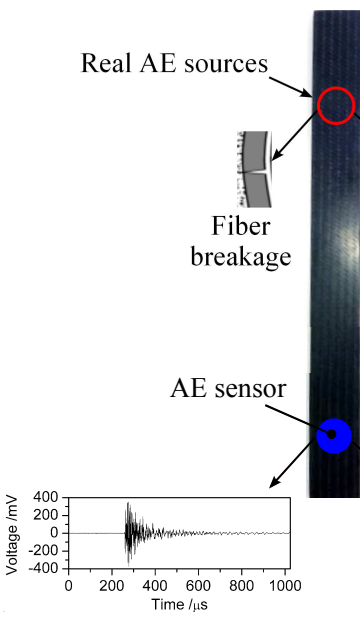

Fiber breakage
$\mathbf{N}_{\text {cycles }}=\mathbf{N}$

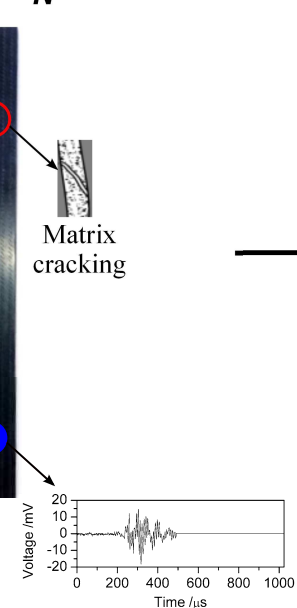

Matrix cracking

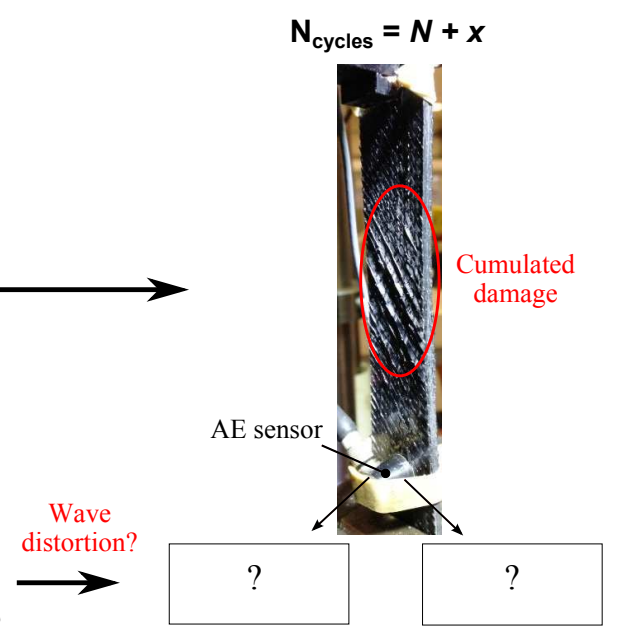

Fiber breakage Matrix cracking

(a)

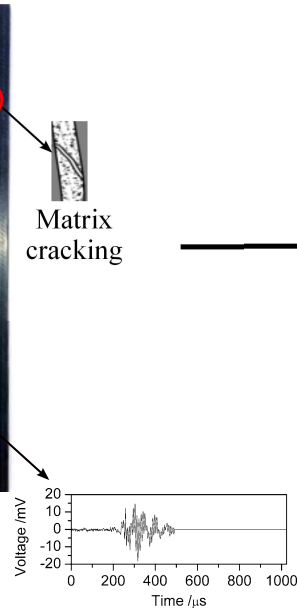

Artificial AE sources reproducing damage-like sources

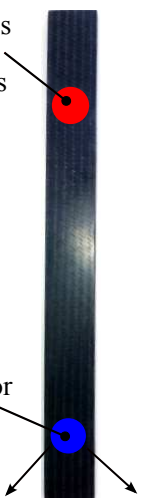

distortions

AE signals similar to the acoustic signatures of local fracture modes

(b)

Figure 1: Purpose of the study. (a) The raised issue: potential evolution of the acoustic signatures of local fracture mechanisms during cyclic loading; and (b) the proposed methodology to quantify the AE wave distortion under the effect of damage accumulation. 


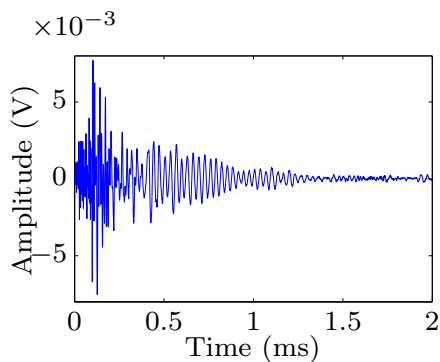

(a)

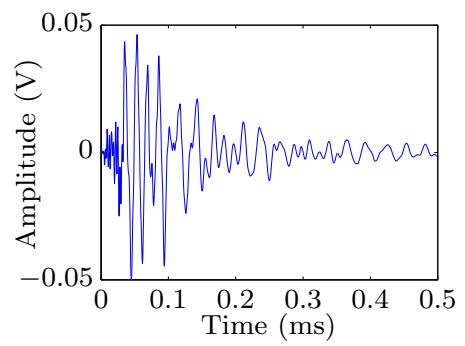

(b)

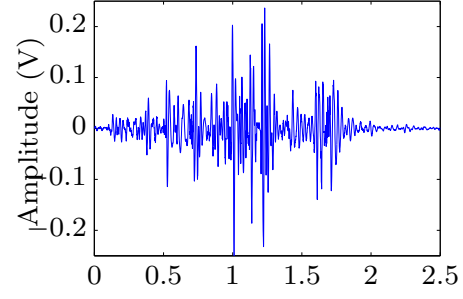

(c)

Figure 2: Some AE signatures of different real damages appeared during a cyclic fatigue test performed on the composite. Artificial AE sources are used to reproduce damage-like AE signatures with similar characteristics as the real damagerelated signatures. 


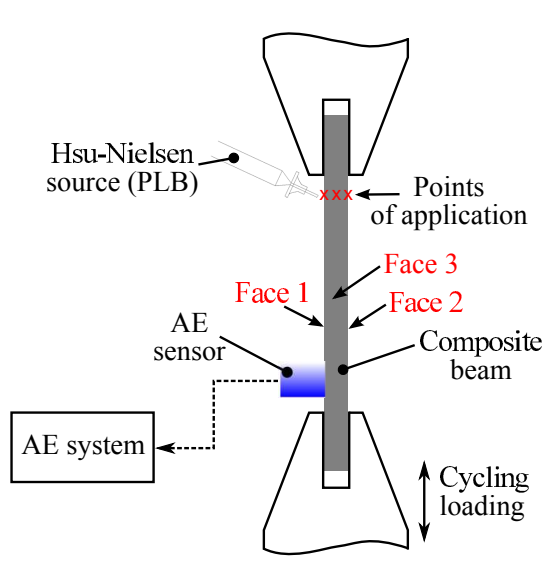

(a) Pencil Lead Break.

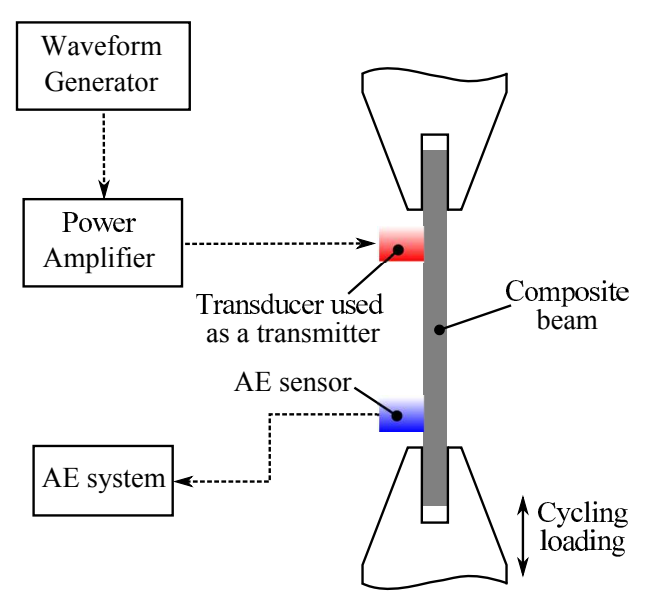

(b) Ultrasonic transducer used as a transmitter.

Figure 3: Test configuration for generating AE damage-like signals using artificial sources. 


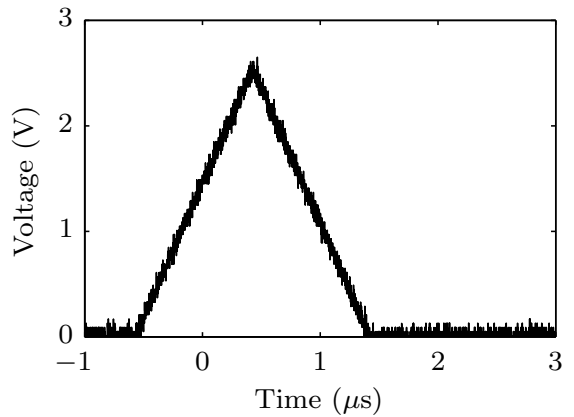

(a) Waveform generator's output signal.

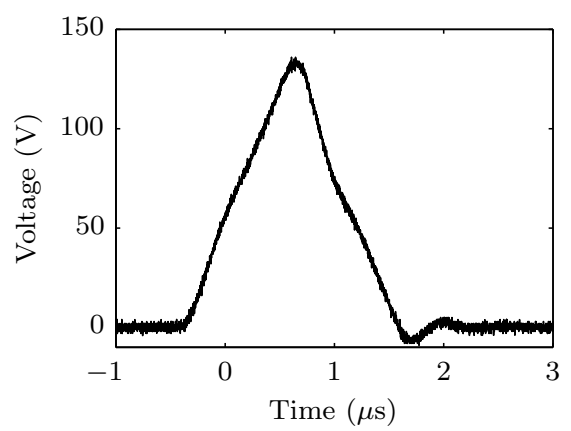

(b) Power amplifier's output signal.

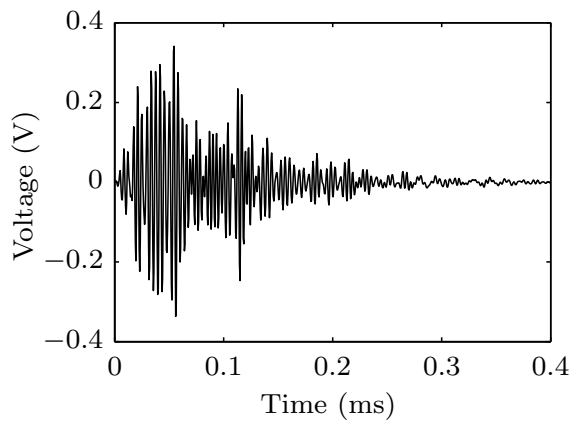

(c) Signal detected by the AE sensor.

Figure 4: Artificial acoustic source created by an ultrasonic transducer used as a transmitter. 


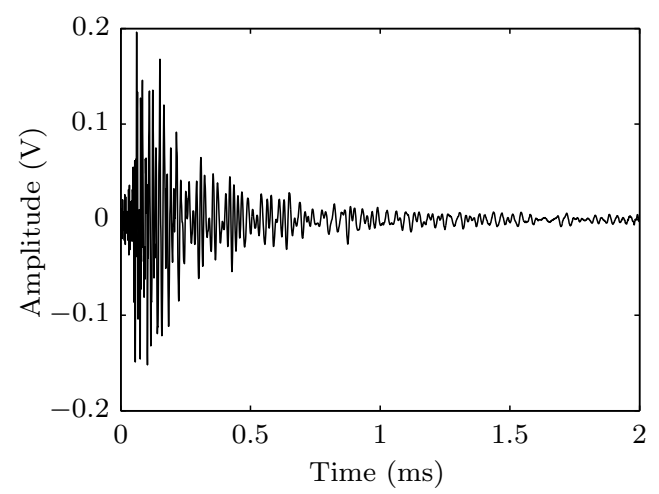

(a) PLB on the top surface ("Face 1").

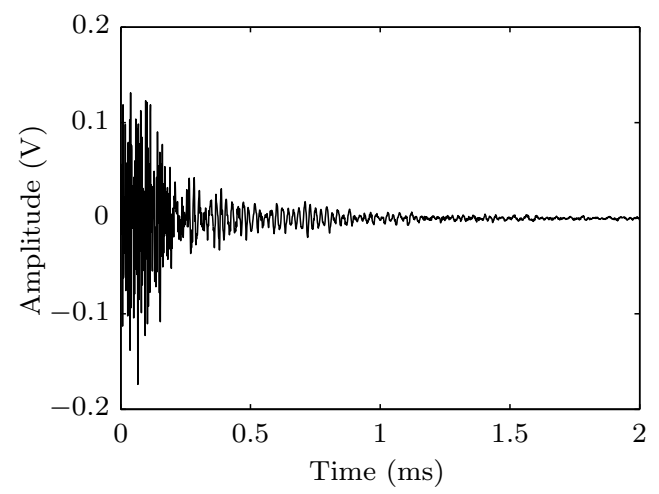

(b) PLB on the edge ("Face 3").

Figure 5: Pencil Lead Break signals detected at the AE sensor level mounted on "Face 1" of a healthy composite material. 


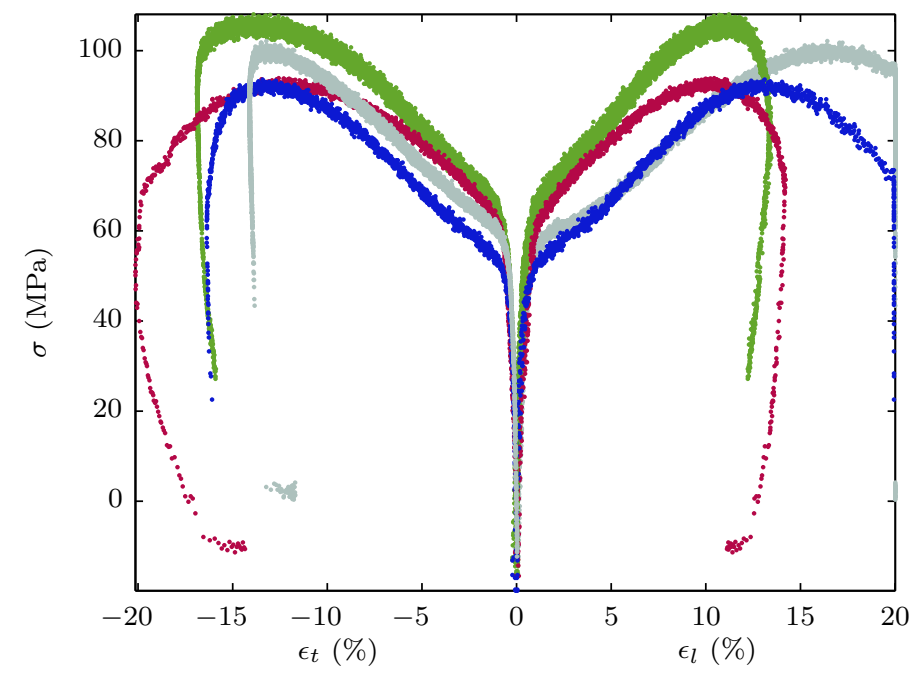

Figure 6: Stress-strain curves obtained from the QS monotonic tests performed on four identical composite specimens, where $\epsilon_{l}$ and $\epsilon_{t}$ are the longitudinal and transverse strains respectively. Each color represents a test performed on one specimen. 


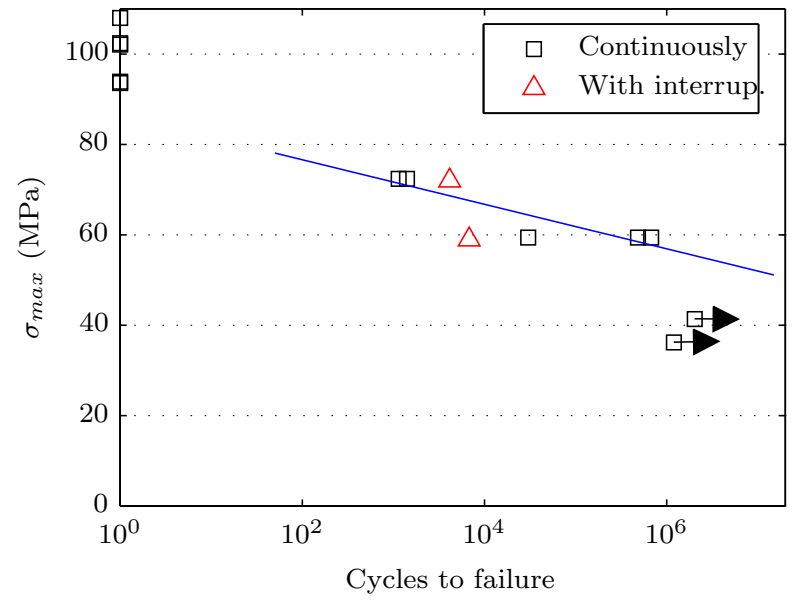

Figure 7: Wöhler curve determined after fatigue cycling tests performed on the composite material at different loading levels at a frequency of $5 \mathrm{~Hz}$ and a stress ratio $R=0.1$. Continuous loading: $35 \%, 40 \%, 57 \%$ and $70 \%$ UTS; with interruptions: $57 \%$ and $70 \%$ UTS. 


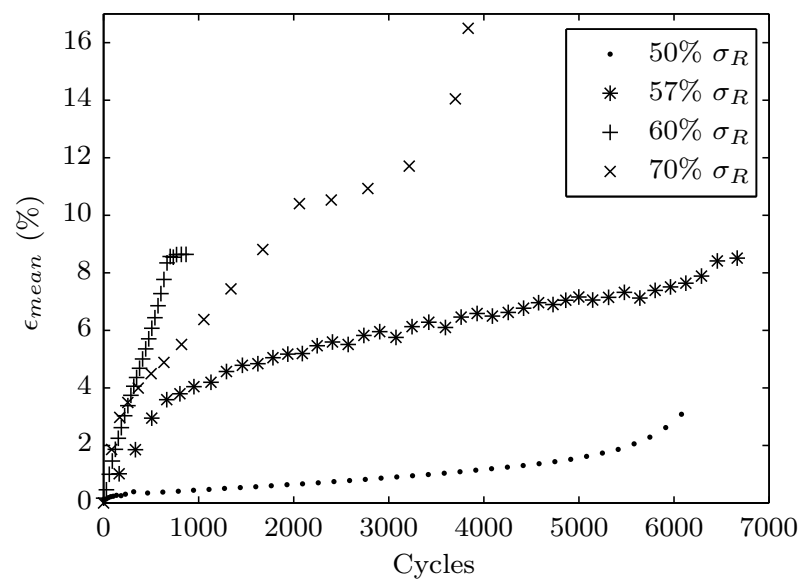

(a)

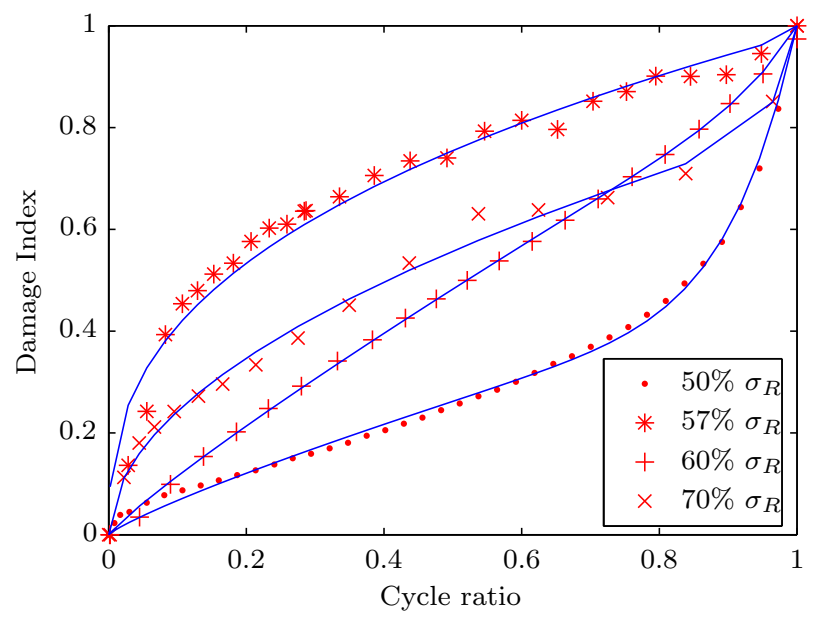

(b)

Figure 8: Damage evolution with cyclic loading: (a) mean longitudinal strain for different loading levels over the number of cycles, (b) experimental damage index and numerical prediction using the Mao-and-Mahadevan's damage model. 


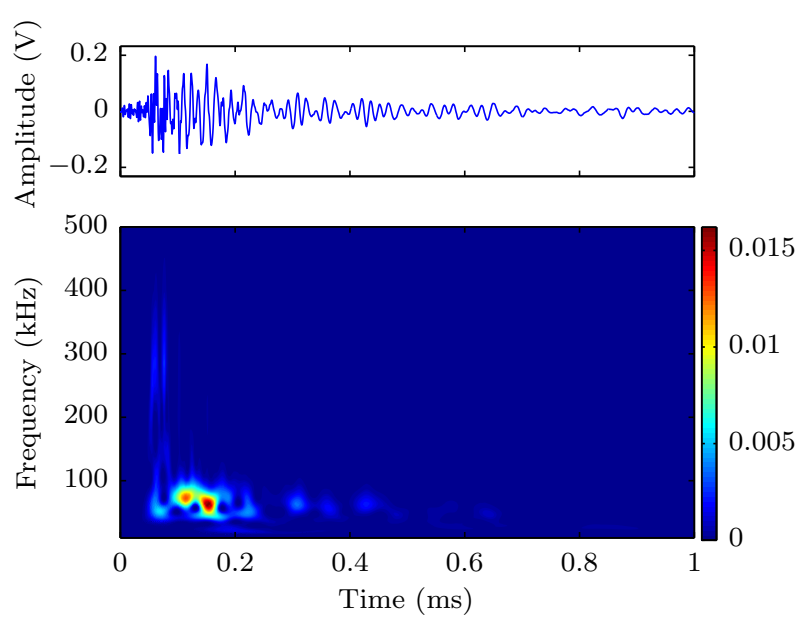

(a) Healthy material: 0 cycles, $D=0$.

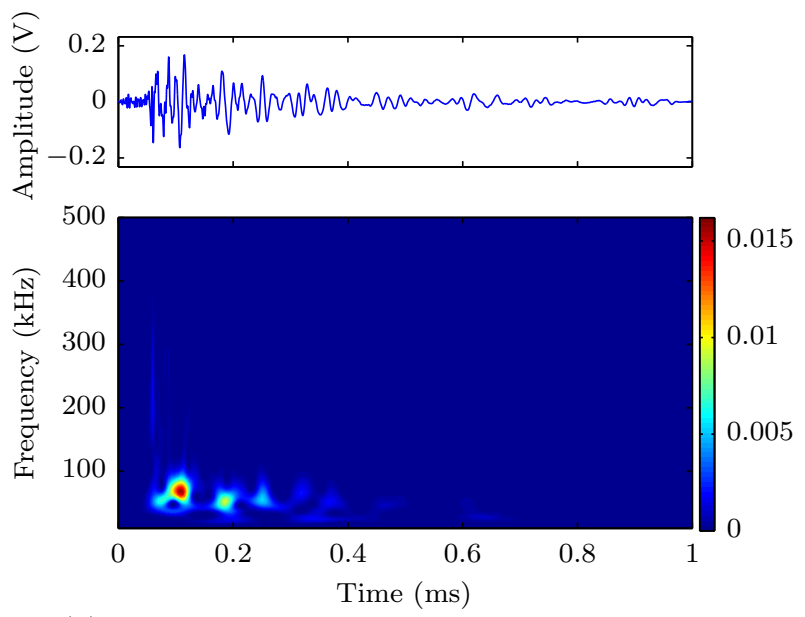

(b) Damaged material: after 820 cycles, $D=0.21$.
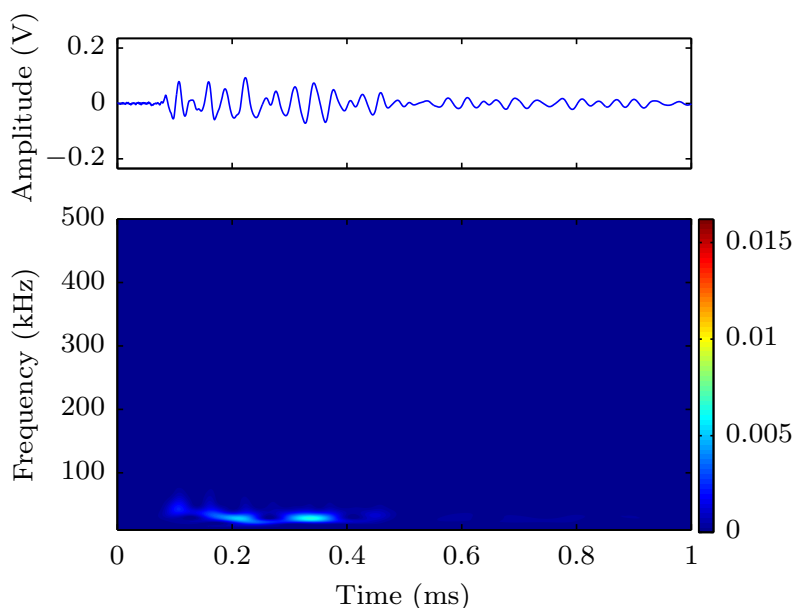

(c) Last measure before failure: after 3835 cycles, $D=1$.

Figure 9: Waveforms distortion with cumulated damage when using a PLB on "Face 1" as AE source. 


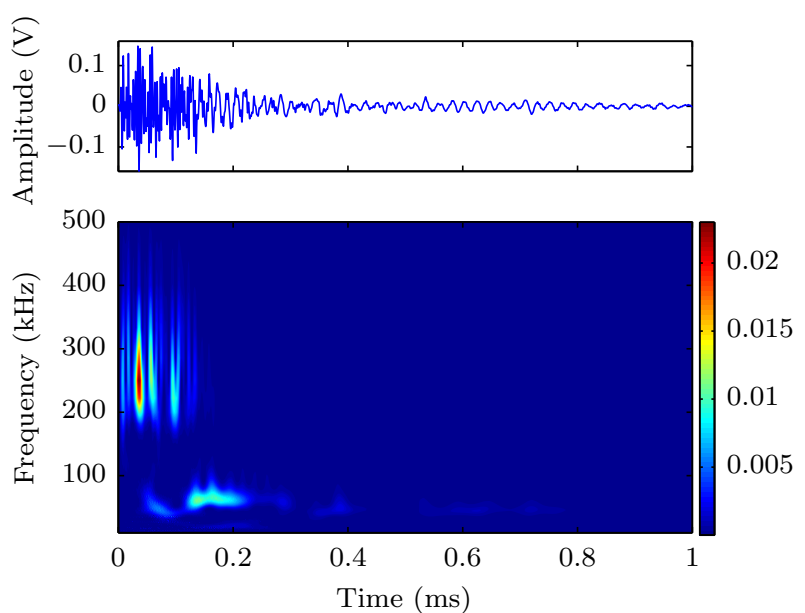

(a) Healthy material: 0 cycles, $D=0$.

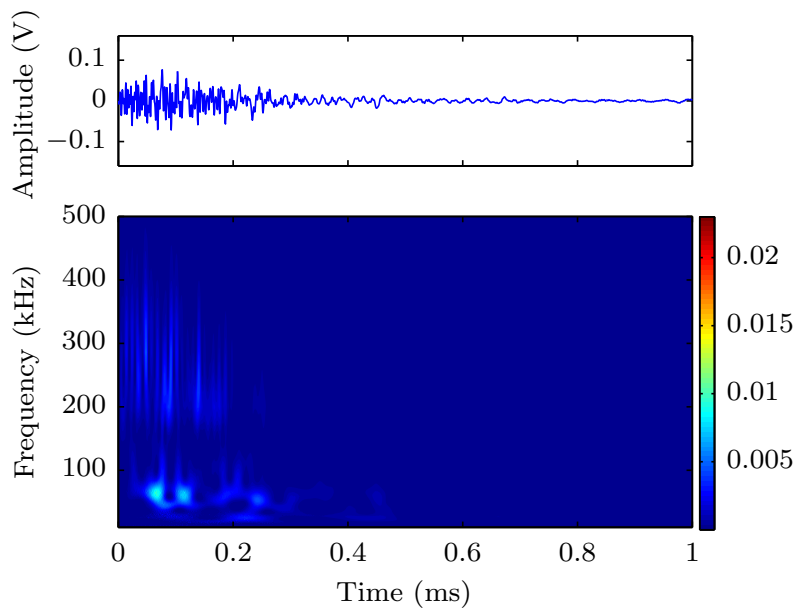

(b) Damaged material: after 820 cycles, $D=0.21$.

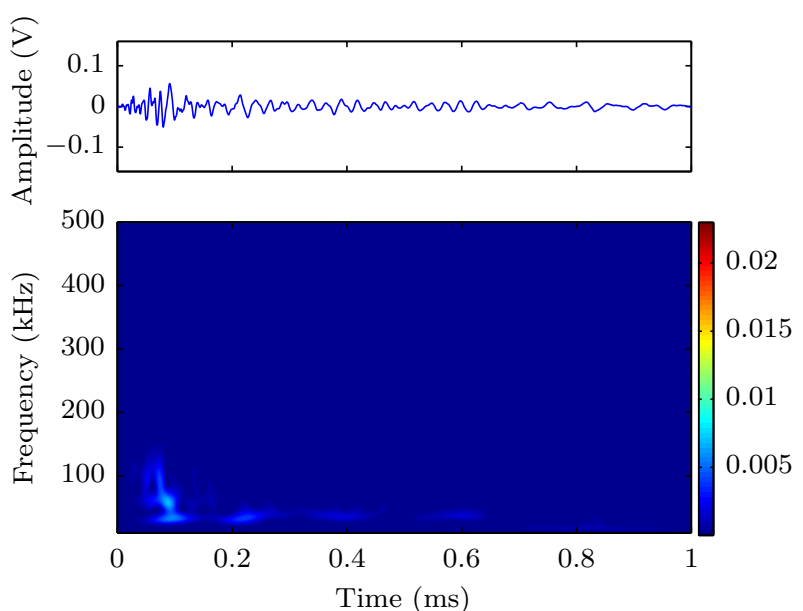

(c) Last measure before failure: after 3835 cycles, $D=1$.

Figure 10: Waveforms distortion with cumulated damage when using a PLB on "Face 3" as AE source. 


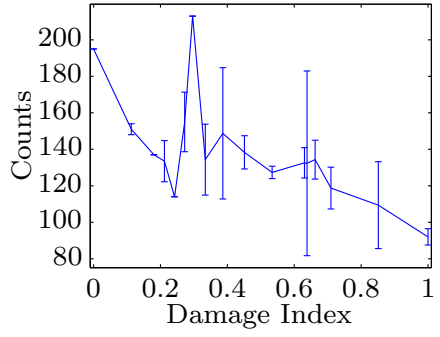

(a)

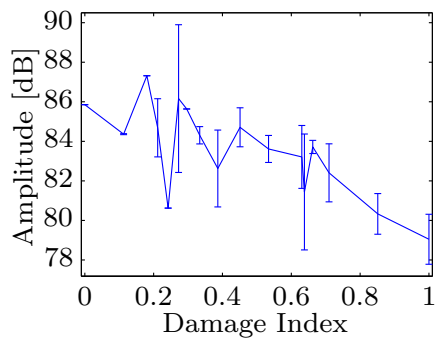

(d)

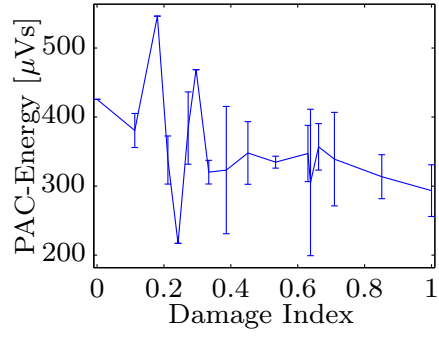

(b)

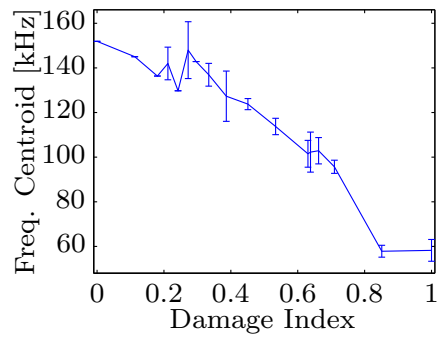

(e)

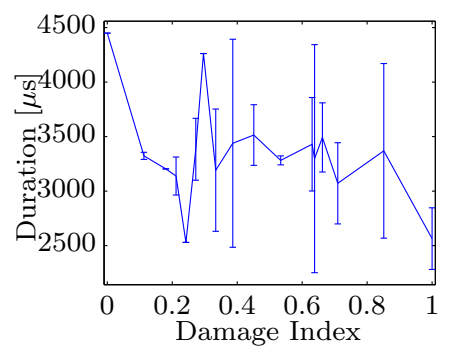

(c)

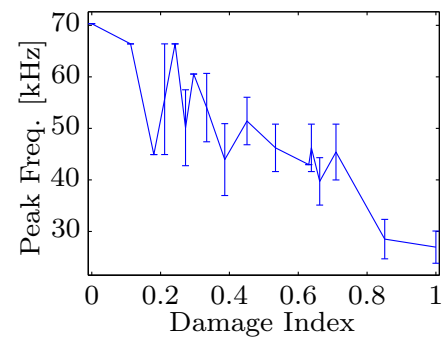

(f)

Figure 11: Evolution of the AE-features with cumulated damage when using a PLB on "Face 1" as AE source. 


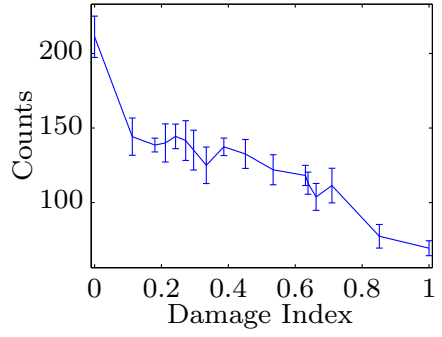

(a)

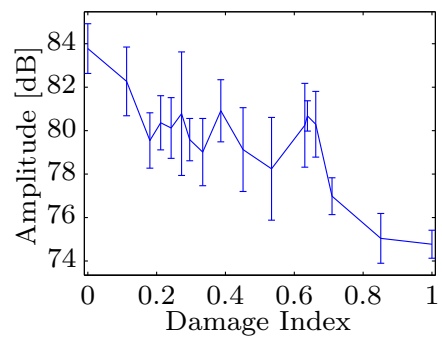

(d)

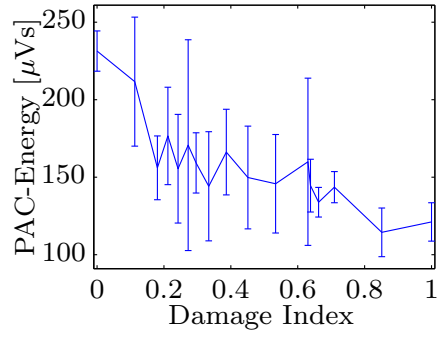

(b)

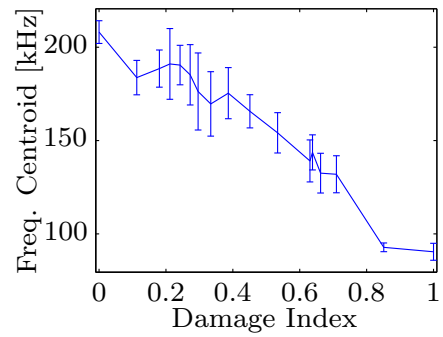

(e)

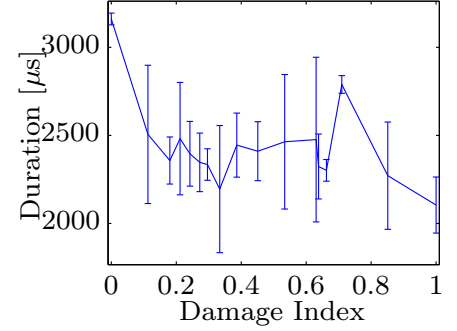

(c)

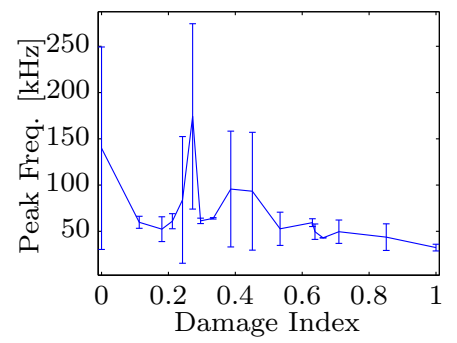

(f)

Figure 12: Evolution of the AE-features with cumulated damage when using a PLB on "Face 3" as AE source. 


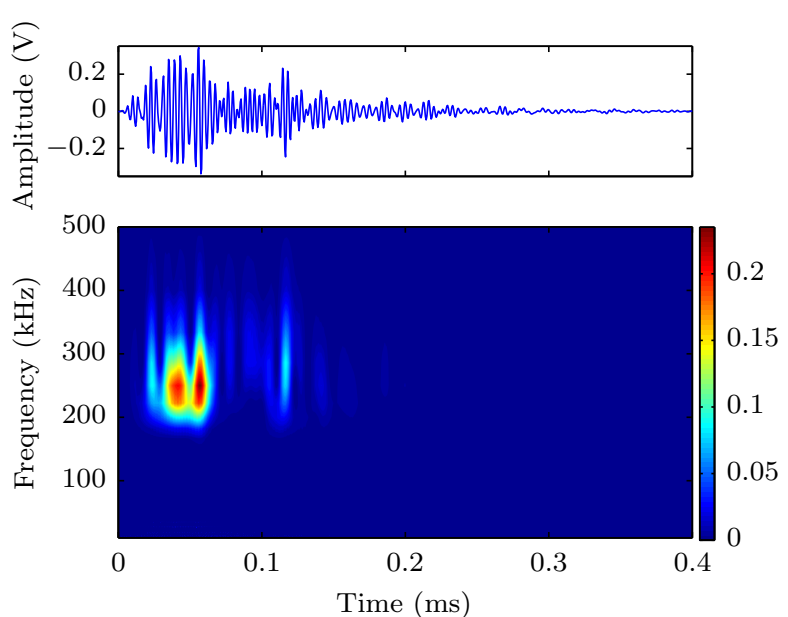

(a) Healthy material: 0 cycles, $D=0$.

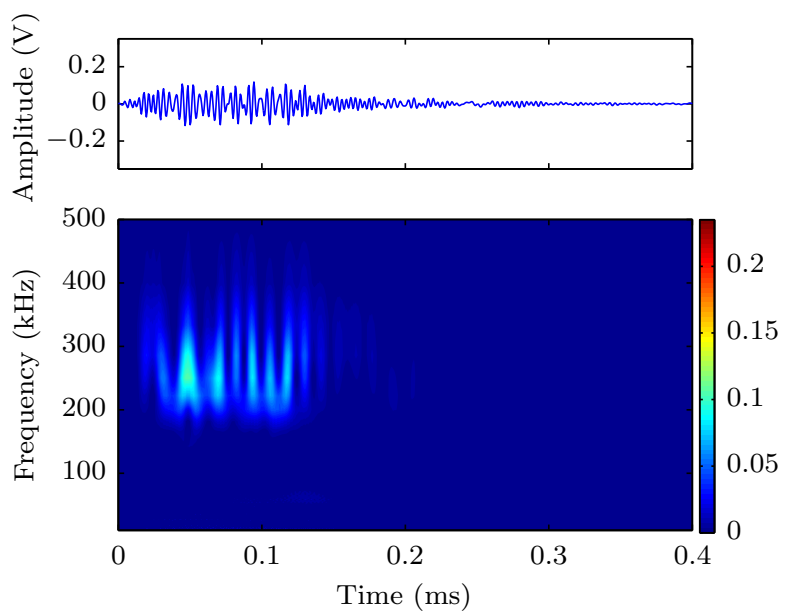

(b) Damaged material: after 820 cycles, $D=0.21$.
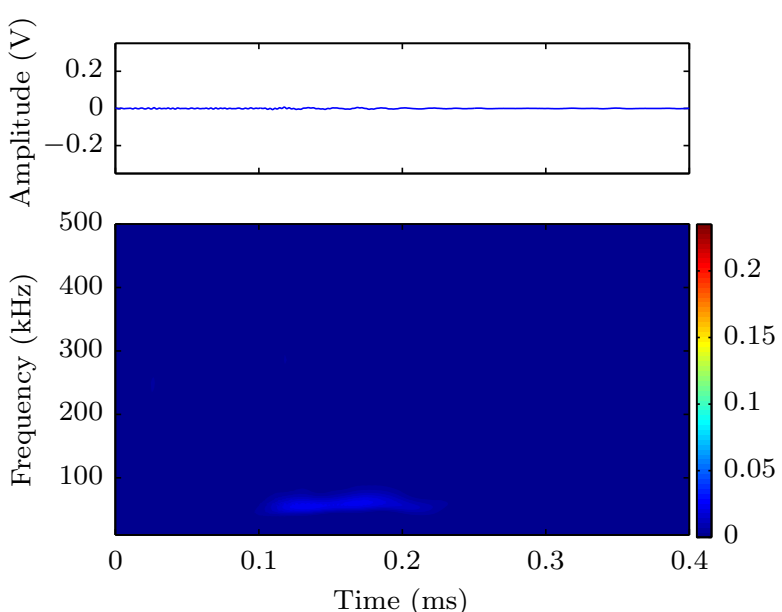

(c) Last measure before failure: after 3835 cycles, $D=1$.

Figure 13: Waveforms distortion with cumulated damage when using an ultrasonic transducer as AE source. 


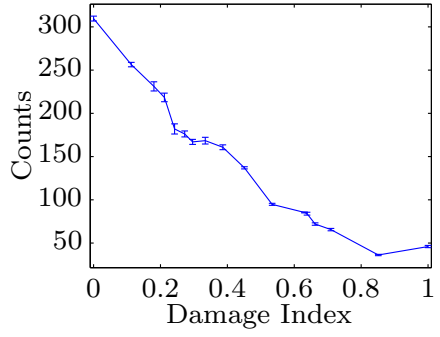

(a)

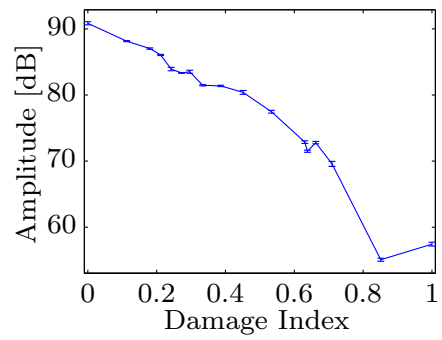

(d)

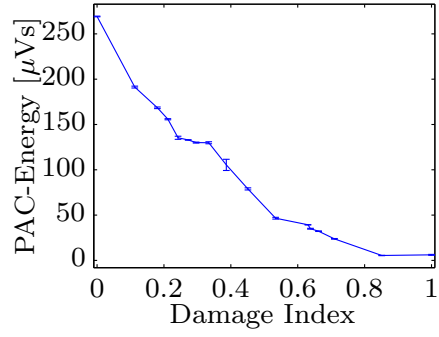

(b)

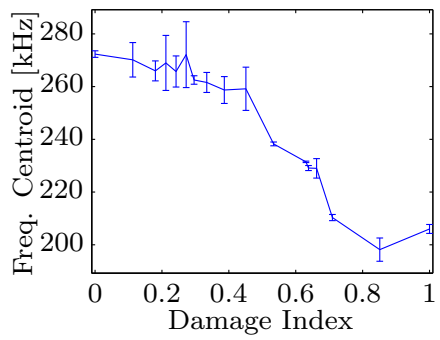

(e)

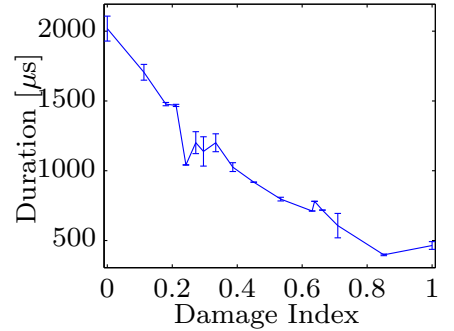

(c)

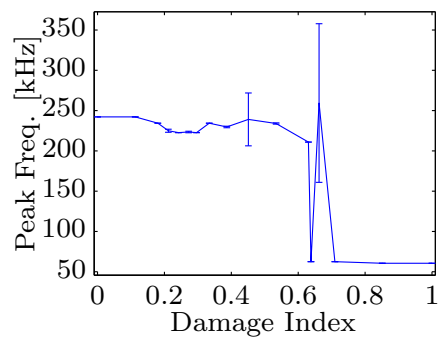

(f)

Figure 14: Evolution of the AE-features with cumulated damage when using an ultrasonic transducer as AE source. 


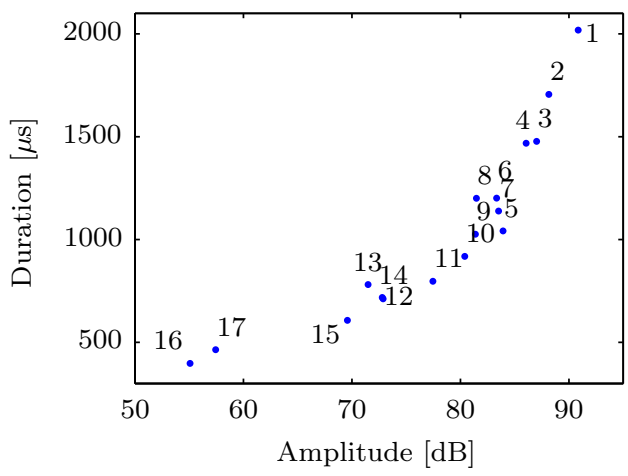

(a)

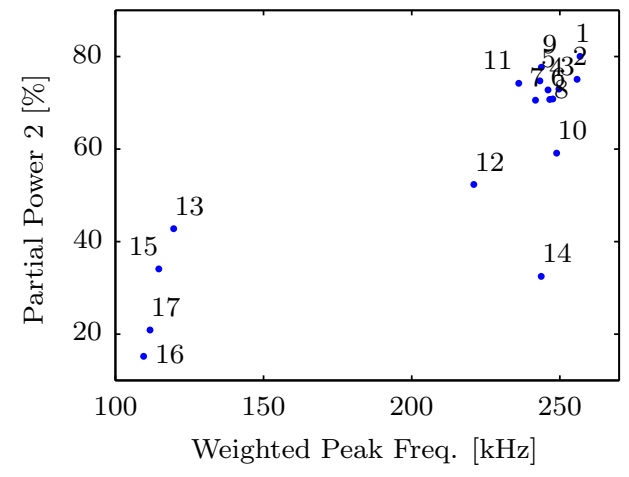

(b)

Figure 15: Modification of the AE-features diagrams of a detected hit during the damage accumulation. AE source reproduced using an ultrasonic transducer. Data point 1 represents $D=0$, and data point 17 represents $D=1$. 